\title{
Organic/Inorganic Superabsorbent Hydrogels Based on Xylan and Montmorillonite
}

\author{
Shuang Zhang, ${ }^{1}$ Ying Guan, ${ }^{1}$ Gen-Que Fu, ${ }^{1}$ Bo-Yang Chen, \\ Feng Peng, ${ }^{1}$ Chun-Li Yao, ${ }^{1}$ and Run-Cang Sun ${ }^{1,2}$ \\ ${ }^{1}$ Institute of Biomass Chemistry and Technology, College of Materials Science and Technology, \\ Beijing Forestry University, Beijing 100083, China \\ ${ }^{2}$ State Key Laboratory of Pulp and Paper Engineering, South China University of Technology, Guangzhou 510640, China \\ Correspondence should be addressed to Feng Peng; fengpeng@bjfu.edu.cn and Chun-Li Yao; chunliyao2006@163.com
}

Received 10 December 2013; Accepted 2 January 2014; Published 12 February 2014

Academic Editor: Ming-Guo Ma

Copyright (C) 2014 Shuang Zhang et al. This is an open access article distributed under the Creative Commons Attribution License, which permits unrestricted use, distribution, and reproduction in any medium, provided the original work is properly cited.

\begin{abstract}
The unique organic/inorganic superabsorbent hydrogels based on xylan and inorganic clay montmorillonite (MMT) were prepared via grafting copolymerization of acrylic acid (AA) and 2-acrylamido-2-methylpropanesulfonic acid (AMPS) with N,Nmethylenebisacrylamide (MBA) as a cross-linking agent and potassium persulfate (KPS) as an initiator. The effect of variables on the swelling capacity of the hydrogels, such as the weight ratios of MMT/xylan, MBA/xylan, and AMPS/AA, was systematically optimized. The results indicated that the superabsorbent hydrogels comprised a porous cross-linking structure of MMT and xylan with side chains that carry carboxylate, carboxamide, and sulfate. The hydrogels exhibit the high compressive modulus $(E)$, about $35-55 \mathrm{KPa}$, and the compression strength of the hydrogels increased with an increment of the MMT content. The effect of various cationic salt solutions $\left(\mathrm{LiCl}, \mathrm{CaCl}_{2}\right.$, and $\left.\mathrm{FeCl}_{3}\right)$ on the swelling has the following order: $\mathrm{Li}^{+}>\mathrm{Ca}^{2+}>\mathrm{Fe}^{3+}$. Furthermore, the influence of $\mathrm{pH}$ values on swelling behaviors showed that the superabsorbent composites retained around $1000 \mathrm{gg}^{-1} \mathrm{over} \mathrm{a}$ wide $\mathrm{pH}$ range of 6.0-10.0. The xylan-based hydrogels with the high mechanical and swelling properties are promising for the applications in the biomaterials area.
\end{abstract}

\section{Introduction}

Superabsorbent hydrogels are slightly cross-linked hydrophilic polymers with a three-dimensional network structure. They can absorb water in the amount from $10 \%$ up to thousands of times based on their dry weight and retain large amounts of aqueous fluids even under some pressure. Due to the special characteristics, these materials have been widely applied in various fields, such as agriculture [1,2], biomedical area $[3,4]$, waste-water treatment $[5,6]$, biosensors [7], and tissue engineering $[8,9]$.

Polysaccharide-based hydrogels are currently attracting much interest for their unique properties, that is, biocompatibility, biodegradability, renewability, and nontoxicity. Various polysaccharides, such as chitosan [10], starch [11], cellulose [12], alginate [13], carrageenan [14], and gellan gum [15], have been investigated on hydrogel formulations. Typically, hemicelluloses are the second most abundant polysaccharides in biomass, which are commonly defined as cell wall heterogeneous polysaccharides. Compared with other polysaccharides, hemicelluloses have been somewhat neglected in research and are normally disposed as organic waste from the forest industry side streams. While recent research has shown that hemicelluloses have significant potential as a material resource for hydrogel preparation. A series of hemicellulosesbased hydrogels were synthesized from galactoglucomannans, via introducing functional monomers with unsaturated bonds to the backbone of hemicelluloses and chemically cross-linking the modified hemicelluloses [16-20]. The hydrogels, presenting good biodegradability, nontoxicity, and controllable swelling capacity, were fully developed for drug delivery systems. In addition, xylan-based hydrogels have also shown potential applications as $\mathrm{pH}$-sensitive controlled drug delivery vehicles by blending aspen hemicelluloses and chitosan in acidic conditions [21]. Furthermore, xylanrich hemicelluloses-based hydrogels were prepared and used 
as a novel porous bioabsorbent by graft copolymerization of acrylic acid and hemicelluloses for absorption of heavy metal ions from aqueous solutions [22, 23]. Therefore, the applications of hemicelluloses in hydrogels field are gradually expanding.

Arabinoxylans (AXs) are the main hemicelluloses of Gramineae, which have been generally present in a variety of tissue of the main cereals of commerce: wheat, rye, barley, oat, rice, corn, and sorghum, as well as other plants: pangola grass, bamboo shoot, and ray grass [24]. Gramineae is similar to hardwood xylan, but the amount of L-arabinose is higher. Hydrogels have been prepared from AXs extracted from wheat bran as controlled release matrices, which were synthesized via the oxidative cross-linking using either chemical (ferulic chloride and ammonium persulphate) or enzymatic (laccase $/ \mathrm{O}_{2}$ and peroxidase $/ \mathrm{H}_{2} \mathrm{O}_{2}$ ) free radical-generating agents [25-27]. The gels present interesting properties like neutral taste and odor, high water absorption capability (up to $100 \mathrm{~g}$ of water per gram of dry polymer), and absence of $\mathrm{pH}$, electrolyte, and temperature susceptibility [28]. However, the water absorption capacity and mechanical strength of the AXs hydrogels are much lower than those of petroleum-based hydrogels such as poly(acrylic acid) and poly(acrylamide) hydrogels. Furthermore, the absence of multistimulus response properties severely restricts their applications. Therefore, more research attention should be paid to develop new approaches for modifying and crosslinking AXs to improve the properties of the hydrogels, such as absorption capacity, mechanical strength, and stimuliresponsive physical properties (normally temperature-, $\mathrm{pH}$-, salt-, or osmosis-controlled changes).

Recently, much attention has been focused on inorganic materials for preparation of superabsorbent composites, such as attapulgite [29], kaolin [30], and sodium silicate [31]. The introduction of inorganic clay into polysaccharides not only reduces production costs but also improves the properties (e.g., swelling ability, gel strength, and mechanical and thermal stability) of hydrogels and accelerates the generation of new materials for special application [32]. Among the clays, montmorillonite (MMT), a layered aluminum silicate with exchangeable cations and reactive $-\mathrm{OH}$ groups on the surface, has been widely used to improve the properties of hydrogels, due to its good absorption, extensive swelling in water and cation exchange capacity [33]. Yet, to the best of our knowledge, there has been no report on the preparation of superabsorbent hydrogels based on xylan and inorganic clays.

Acrylic acid (AA) and 2-acrylamido-2-methylpropanesulfonic acid (AMPS) are important monomers that are widely used for the preparation of functional hydrogels. AMPS is hydrophilic monomer containing nonionic and anionic groups; meanwhile, AA is anionic monomer. The incorporation of ionic groups in the superabsorbent is known to increase their swelling capacity, while the nonionic groups can improve their salt tolerance. In this paper, a unique organic/inorganic hydrogel was prepared by grafting copolymerization of AA and AMPS monomers along the chains of AXs in the presence of MMT. The intermolecular interaction and morphological change of the hydrogels were characterized by FT-IR spectra and scanning electron microscope (SEM). Moreover, the swelling properties and behaviors under different $\mathrm{pH}$ and salt concentrations were investigated.

\section{Experimental}

2.1. Materials. Xylan was isolated from bamboo (Phyllostachys pubescens) holocellulose obtained by using $3 \%$ $\mathrm{NaOH}$ at $75^{\circ} \mathrm{C}$ for $3 \mathrm{~h}$ with a solid to liquid ratio of $1: 25$ $\left(\mathrm{g} \cdot \mathrm{mL}^{-1}\right)$. The holocellulose was obtained by delignification of the extractive-free bamboo (40-60 mesh) with $6 \%$ sodium chlorite in acidic solution ( $\mathrm{pH}$ 3.6-3.8, adjusted by $10 \%$ acetic acid) at $75^{\circ} \mathrm{C}$ for $2 \mathrm{~h}$. The composition of neutral sugars and uronic acids and the molecular weights of the hemicellulosic samples were determined according to the literature [34]. The sugar composition of the xylan (83.5\% xylose, $5.1 \%$ arabinose, $4.2 \%$ glucose, $0.4 \%$ galactose, and $6.8 \%$ glucuronic acid (relatively molar percent)) was tested by high performance anion exchange chromatography (HPAEC). The molecular weights obtained by gel permeation chromatography (GPC) showed that the native xylan had a weight average molecular weight $(\mathrm{Mw})$ of $13,420 \mathrm{~g} \cdot \mathrm{mol}^{-1}$ and a polydispersity of 4.1, corresponding to a degree of polymerization of 88. 2-Acrylamido-2-methyl-1-propanesulfonic acid (AMPS) and montmorillonite (MMT) were purchased from A Johnson Mattey Company. N,N-Methylenebisacrylamide (MBA) and potassium persulfate (KPS) were purchased from Tianjin Jinke Refined Chemical Engineering Research Institute, China. All of these chemicals were used without any further purification. AA (Beijing Yili Fine Chemical Co., Ltd., China) was purified by distillation under reduced pressure to remove the inhibitor hydroquinone before use. All other reagents used were analytical grade, and all solutions were of prepared with distilled water.

2.2. Preparation of Hydrogels. Xylan $(1.0 \mathrm{~g})$ was dissolved in $35.0 \mathrm{~mL}$ of distilled water in a three-neck reactor equipped with a mechanical stirrer, a reflux condenser, and a nitrogen line at $85^{\circ} \mathrm{C}$ until a homogeneous solution was obtained. Then appropriate amounts $(0.00-0.12 \mathrm{~g})$ of MMT were added to this solution with stirring to form a uniform sticky solution under nitrogen. After cooling the reactant to $70^{\circ} \mathrm{C}$, $0.08 \mathrm{~g}$ of KPS were added, stirred, and kept for $10 \mathrm{~min}$ to generate radicals. Subsequently, the mixture of AA (1.43$2.86 \mathrm{~g}$, neutralization degree of $70 \%$ with sodium hydroxide solution), AMPS (1.14-2.57 g), and MBA (0.05-0.25 g) was added to the flask. All the reactions were carried out under nitrogen, and the reaction mixture was continuously stirred for $4 \mathrm{~h}$. At the end of the propagation reaction, the gel product was poured into excess ethanol $(200 \mathrm{~mL})$ and remained for $48 \mathrm{~h}$ to dewater. Then, the dewatered product was dried to constant mass at $70^{\circ} \mathrm{C}$, grounded, and passed through 100 mesh sieve. Finally, the powdered products were stored away from moisture, heat, and light. The feed compositions of all samples are listed in Table 1. 
TABLE 1: The reaction conditions for xylan- $g$-poly(AA-AMPS)/MMT hydrogels.

\begin{tabular}{lcccc}
\hline Sample codes & MMT/xylan $\left(\mathrm{g} \mathrm{g}^{-1}\right)$ & AMPS $(\mathrm{g})$ & MBA $(\mathrm{g})$ & 0.10 \\
\hline 1 & - & 1.00 & 0.10 & 2.00 \\
2 & 0.03 & 1.00 & 0.10 & 2.00 \\
3 & 0.05 & 1.00 & 0.10 & 2.00 \\
4 & 0.08 & 1.00 & 0.10 & 2.00 \\
5 & 0.11 & 1.00 & 0.05 & 2.00 \\
6 & 0.08 & 2.00 & 0.10 & 2.00 \\
7 & 0.08 & 2.00 & 0.15 & 2.00 \\
8 & 0.08 & 2.00 & 0.20 & 2.00 \\
9 & 0.08 & 2.00 & 0.25 & 2.00 \\
10 & 0.08 & 2.00 & 0.10 & 2.00 \\
11 & 0.08 & 1.14 & 0.10 & 2.28 \\
12 & 0.08 & 1.78 & 0.10 \\
13 & 0.08 & 2.00 & 0.10 \\
15 & 0.08 & 2.33 & 0.10 \\
\hline
\end{tabular}

\subsection{Method of Characterization}

2.3.1. FT-IR Spectroscopy. FT-IR spectra of the MMT, xylan, xylan-g-poly(AA-AMPS), and xylan- $g$-poly(AA-AMPS)/ MMT hydrogels were recorded using a Thermo Scientific Nicolet iN 10 FT-IR Microscopy (Thermo Nicolet Corporation, Madison, WI) equipped with a liquid nitrogen cooled MCT detector. Dried samples were grounded and palletized using $\mathrm{BaF}_{2}$ and their spectra were recorded from 4000 to $650 \mathrm{~cm}^{-1}$ at a resolution of $4 \mathrm{~cm}^{-1}$ and 128 scans per sample.

2.3.2. Surface Morphology of the Hydrogels. The equilibriumswollen samples of the hydrogels in deionized water at room temperature were quickly frozen and then freeze-dried for morphological analysis. Scanning electron microscopy (SEM) of the hydrogel samples was carried out with a Hitachi S-3400N II (Hitachi, Japan) instrument at $15 \mathrm{kV}$. Prior to taking pictures, the samples were sputter-coated with a thin layer of gold. Images were obtained at magnifications ranging from $200 \mathrm{x}$ to $5000 \mathrm{x}$, which was dependent on the feature to be traced.

2.3.3. Swelling Measurements. The preweighted dry hydrogels were immersed into excessive distilled water to reach a state of equilibrium swelling. The swollen superabsorbent was filtered using 100-mesh sieve and drained for 20 min until no free water remained. After weighing the swollen hydrogels, the equilibrium water absorption was calculated by using the following equation:

$$
Q_{\mathrm{eq}}=\frac{W_{2}-W_{1}}{W_{1}}
$$

where $Q_{\mathrm{eq}}$ is the equilibrium water absorption defined as grams of water per gram of sample; $W_{1}$ and $W_{2}$ are the mass of sample before and after swelling, respectively.
2.3.4. Mechanical Measurement. Dynamic mechanical analysis (DMA, TA Instruments Q800 Series) was used to determine the compressive modulus of the swollen hydrogel samples. To reach swelling equilibrium, hydrogels were incubated in distilled water for $24 \mathrm{~h}$ at room temperature before test. The disk-shaped samples were $1 \mathrm{~cm} \times 0.5 \mathrm{~cm}$ (diameter $\times$ height) in dimension and were tested in compression mode at $25^{\circ} \mathrm{C}$. Rheological measurements were carried out at $25^{\circ} \mathrm{C}$ on ARES-RFS III rheometer (TA Instruments, USA). The mixture of xylan (1.0 g), KPS ( $0.08 \mathrm{~g})$, AA (1.0 or $2.0 \mathrm{~g})$, MBA $(0.05-0.25 \mathrm{~g})$, and MMT $(0.00-0.12 \mathrm{~g})$ was stirred to form a homogeneous solution. This hybrid system was quickly transferred into rheometer for testing.

2.3.5. Swelling in Various Salt Solutions. The swelling capacity of the hydrogels was measured in different concentrations $\left(0.5,1.0,1.5,2.0\right.$, and $\left.2.5 \mathrm{~mol} \cdot \mathrm{L}^{-1}\right)$ of $\mathrm{LiCl}, \mathrm{CaCl}_{2}$, and $\mathrm{FeCl}_{3}$ salt solutions according to the above method described for swelling measurement in distilled water.

2.3.6. Swelling at Various $p H s$. Individual solutions with acidic and basic $\mathrm{pHs}$ were prepared by the dilution of $\mathrm{NaOH}$ $(\mathrm{pH} 12.0)$ and $\mathrm{HCl}(\mathrm{pH} 2.0)$ solutions to achieve $\mathrm{pH} \geq 6.0$ and $<6.0$, respectively. The $\mathrm{pH}$ values were precisely checked by a $\mathrm{pH}$ meter (PB-10, Sartorius). Then, the preweighted dried hydrogels were used for the swelling measurements according to the above method described for swelling measurement in distilled water.

2.3.7. Water Retention Measurement. The water retention (WR) was determined by centrifuging the water-swollen hydrogels at $2000 \mathrm{rpm}$. The weight of the hydrogels was determined every $30 \mathrm{~s}$. The WR of the hydrogels was calculated according to

$$
\mathrm{WR}(\%)=\frac{m_{2}}{m_{1}} \times 100 \%,
$$


where $m_{1}$ is the weight of the fully swollen hydrogel and $m_{2}$ is the weight of the hydrogel centrifuged for different times at $2000 \mathrm{rpm}$.

\section{Results and Discussion}

3.1. Synthesis and Spectral Characterization. The superabsorbent hydrogel was prepared by the graft copolymerization of acrylic acid (AA) and 2-acrylamido-2-methyl-1propanesulfonic acid (AMPS) onto xylan in the presence of a cross-linking agent (MBA), powdery montmorillonite (MMT), and potassium persulfate (KPS) as an initiator. The persulfate initiator was decomposed under heating to produce sulfate anion radicals that abstract hydrogen atoms from the hydroxyl groups of the xylan backbones. Therefore, this redox system resulted in active centers capable of radically initiating the polymerization of AA and AMPS, leading to a graft copolymer. Since a cross-linking agent (MBA) was present in this system, the copolymer comprised a crosslinked structure. The MMT in the polymerization reaction can also be considered as a cross-linking agent [35]. The proposed mechanism for the grafting and chemically crosslinking reactions is outlined in Figure 1.

Infrared spectroscopy was carried out to confirm the chemical structure of the superabsorbent hydrogel. FT-IR spectra of MMT, xylan, xylan- $g$-poly(AA-AMPS), and xylan- $g$-poly(AA-AMPS)/MMT superabsorbent hydrogel are shown in Figure 2. In the spectrum (see Figure 2(c)) of xylan, the region between $3500 \mathrm{~cm}^{-1}$ and $1800 \mathrm{~cm}^{-1}$ presents two major peaks at about $3411 \mathrm{~cm}^{-1}$ (corresponding to the absorption of stretching of the hydroxyl groups) and at $2911 \mathrm{~cm}^{-1}$ (corresponding to the $\mathrm{C}-\mathrm{H}$ stretching of the $\mathrm{CH}_{2}$ groups). The absorption peak at $1600 \mathrm{~cm}^{-1}$ is related to the uronic acid carboxylate [36]. The bands at the range of 1452 and $1048 \mathrm{~cm}^{-1}$ are assigned to the $\mathrm{C}-\mathrm{H}$ and $\mathrm{C}-\mathrm{O}$ bond stretching frequencies. The low intensity of the peaks at 990 and $1166 \mathrm{~cm}^{-1}$ suggests the presence of arabinosyl units, which have been reported to be attached only at position 3 of the xylopyranosyl constituents [37]. A sharp band at $895 \mathrm{~cm}^{-1}$ is due to $\beta$-glycosidic linkages between the sugar units. On comparing the spectra of xylan and xylang-poly(AA-AMPS) (see Figure 2(d)), new characteristic absorption bands at 1651,1558 , and $1442 \mathrm{~cm}^{-1}$ are assigned to the stretching vibration of $\mathrm{C}=\mathrm{O}$, asymmetrical stretching vibration of $\mathrm{COO}^{-}$, and symmetrical stretching vibration of $\mathrm{COO}^{-}$, respectively [38]. Moreover, the characteristic absorption peaks of AMPS units are shown at 1400, 1040, and $627 \mathrm{~cm}^{-1}$, which are attributed to $\mathrm{C}-\mathrm{N}$ stretching vibration of the amide, $\mathrm{S}-\mathrm{O}$ stretching vibration of $-\mathrm{SO}_{3} \mathrm{H}$, and $\mathrm{C}-\mathrm{S}$ stretching vibration, respectively [39]. These bands indicated that AA and AMPS monomers were actually grafted onto the backbone of xylan.

In the spectrum (see Figure 2(a)) of MMT, the characteristic vibration bands are shown at 3400 and $3630 \mathrm{~cm}^{-1}$, which correspond to $-\mathrm{OH}$ stretching band for absorbed interlayer water and $-\mathrm{OH}$ stretching band for $\mathrm{Al}-\mathrm{OH}$, respectively. The absorption peaks at 1631 and $1423 \mathrm{~cm}^{-1}$ are attributed to the deformation vibration of the hydroxyl groups. The characteristic peaks at 1150 and $1090 \mathrm{~cm}^{-1}$ are due to Si$\mathrm{O}$ stretching (out-of plane) for MMT and $\mathrm{Si}-\mathrm{O}$ stretching (in plane) vibration for layered silicates, respectively. The peaks at 915,845 , and $796 \mathrm{~cm}^{-1}$ are assigned to $\mathrm{Al}-\mathrm{Al}-\mathrm{OH}$, $\mathrm{Al}-\mathrm{Mg}-\mathrm{OH}$, and $\mathrm{Si}-\mathrm{O}-\mathrm{Al}$ bending vibrations, respectively [40-42]. As can be seen, compared to the spectrum of MMT (Figure 2(b)), the intensities of absorption bands at $3630 \mathrm{~cm}^{-1}$ ascribed to $-\mathrm{OH}$ of MMT disappeared in the spectrum of xylan- $g$-poly(AA-AMPS)/MMT (Figure 2(a)). In addition, the intensity of the absorption peaks due to $\mathrm{Si}-\mathrm{O}$ stretching also decreased. These results indicated that MMT participated in polymerization reaction through its active $\mathrm{OH}$ groups and chemically cross-linked with polymer chains. Therefore, it could be concluded that the superabsorbent hydrogel product comprised a cross-linking structure of xylan and MMT with side chains carrying carboxylate, carboxamide, and sulfate.

3.2. Morphological Analysis. The morphologies of the freeze-dried xylan- $g$-poly(AA-AMPS) and xylan- $g$ poly(AA-AMPS)/MMT composites are depicted in Figure 3, respectively. Obviously, the surface morphology of the xylan- $g$-poly(AA-AMPS)/MMT hydrogel is different from that of xylan- $g$-poly(AA-AMPS). It could be observed that the cross-linked xylan-g-poly(AA-AMPS) (Figure 3(a)) displayed a porous structure with many large pores. However, for hydrogel containing MMT (Figure 3(b)), the pore size became smaller and it showed a sheet-like structure with significant interconnection forming a three-dimensional network, which was beneficial for the diffusion of aqueous fluid into the superabsorbent polymer and increasing the water absorption rate $[43,44]$. In addition, the degree of dispersion of clay micropowder in the polymer matrix is more important for an organic-inorganic composite $[45,46]$. As can be seen from Figures 3(c) and 3(d), the microstructure of pure MMT clay was flaky (Figure 3(c)), while these clays were randomly dispersed in the polymer matrix and almost embedded within xylan- $g$-poly(AA-AMPS) in the composites (Figure 3(d)), and no flocculation of MMT particles could be observed. These SEM results confirmed that the MMT was finely dispersed in the composite to form a homogeneous composition.

3.3. Mechanical Properties of Hydrogels. The mechanical properties of the xylan-based hydrogels with different ratios of MMT to xylan have been determined. Figure 4(a) presents the typical compressive modulus-strain curves of xylanbased hydrogels at room temperature. Obviously, all the samples exhibited the high compressive modulus $(E)$, about $35-55 \mathrm{KPa}$. This indicated that the hydrogels had excellent mechanical properties. As expected, the compressive modulus of the hydrogels increased with the increment of the MMT content in the hydrogels, in the order Gel 5> Gel 4> Gel 3> Gel 2> Gel 1. The results strongly demonstrated that MMT contributed to the enhancement of the mechanical properties of the hydrogels. On the other hand, the strains of hydrogels decrease from $92 \%$ to $66 \%$, when the MMT content was increased in the hydrogel. 


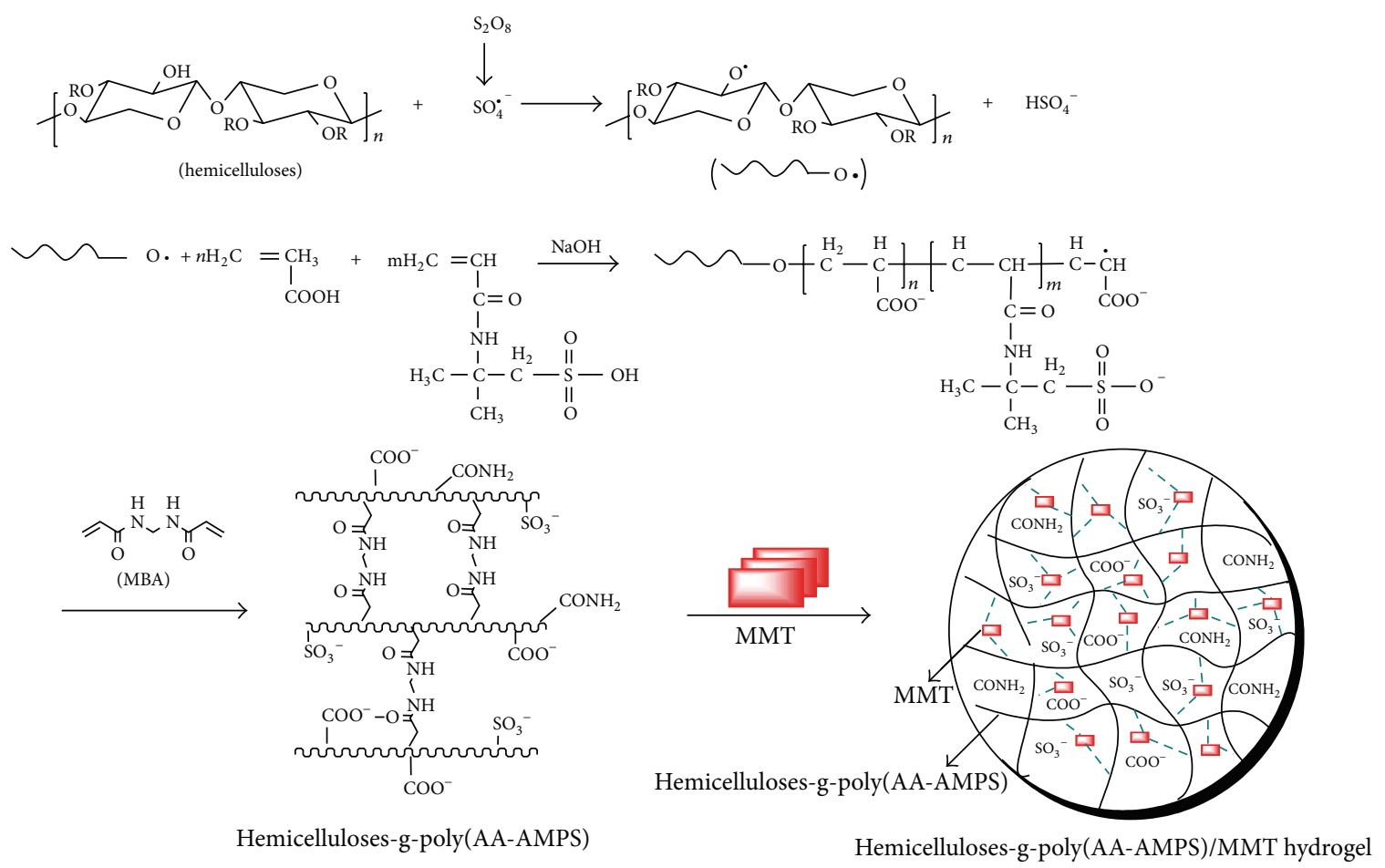

FIGURE 1: Proposed reaction mechanism for synthesis of xylan- $g$-poly(AA-AMPS)/MMT superabsorbent hydrogels.

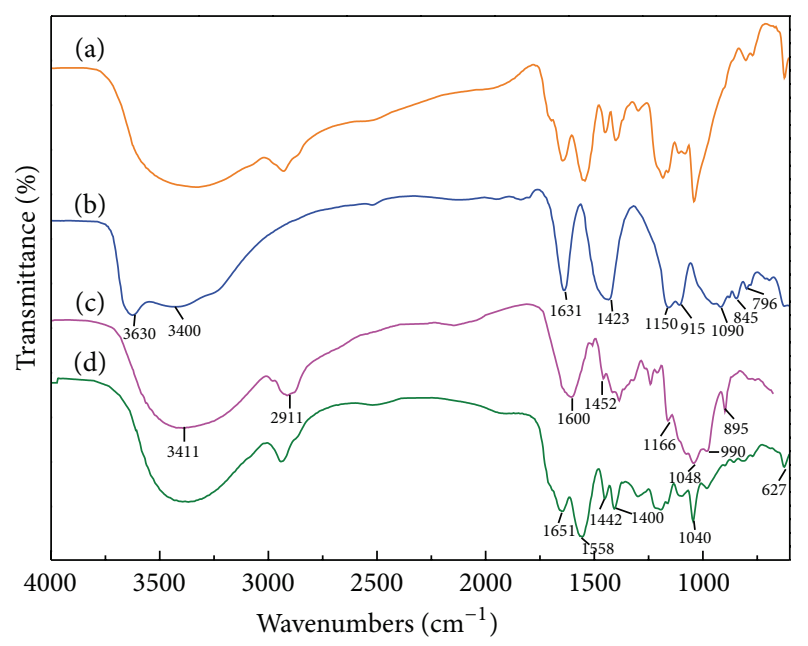

Figure 2: FT-IR of (a) xylan-g-poly(AA-AMPS)/MMT, (b) MMT, (c) xylan and (d) xylan-g-poly(AA-AMPS).

To monitor the gelation process, a time sweep measurement for viscoelastic properties of each sample was carried out at $25^{\circ} \mathrm{C}$ [47]. Figures $4(\mathrm{~b})$ and $4(\mathrm{c})$ show the storage modulus $\left(G^{\prime}\right)$ of hydrogels with different MMT concentrations and various MBA contents, respectively. Apparently, a significant increase of $G^{\prime}$ values at about $300 \mathrm{~s}$ in Figure 4(b) indicated that the rapid gelation process and phase separation occurred during the initial stage. Moreover, the maximum storage modulus of the hydrogels increased with the increase of the MMT/xylan weight ratios from 0.00 to 0.11 . It was further proved that the MMT played an important role in improving the strength of hydrogels. Meanwhile, Figure 4(c) shows the time dependence of the storage modulus of the hydrogels with different MBA contents. Cross-linking agent induced a stable network with the polymers by covalent bonds; thus, the increment of MBA content led to the regular increase of the maximum storage modulus of the hydrogels.

3.4. Effect of MMT Content on Swelling Capacity. The influence of MMT/xylan weight ratio on water absorbency of the superabsorbent hydrogels is shown in Figure 5. It is obvious that MMT content is an important factor influencing water absorbency of the hydrogels. Increasing MMT/xylan weight ratios from 0.00 to 0.08 caused an increment in water absorbency. The maximum water absorbency $\left(1423 \mathrm{~g} \mathrm{~g}^{-1}\right)$ was obtained at weight ratio of MMT/xylan (0.08). This trend was attributed to the fact that the active - $\mathrm{OH}$ groups of MMT could react with the $-\mathrm{OH},-\mathrm{SO}_{3} \mathrm{H}$, and $-\mathrm{COOH}$ groups of the polymeric chains, as indicated by FT-IR spectra (Figure 2). Hence, it can relieve the entanglement of graft polymeric chains and weaken the hydrogen-bonding interaction among hydrophilic groups, which decreases the physical crosslinking degree and improves polymeric network. As a result, the water absorbency can be enhanced by introducing moderate amount of MMT. However, a further increase of MMT caused a decrease in water absorbency. This phenomenon may be attributed to the fact that the MMT can act as an additional cross-linking point in the polymeric network to decrease the elasticity of polymers. Additionally, the excess of MMT would also decrease the hydrophilicity as well as 


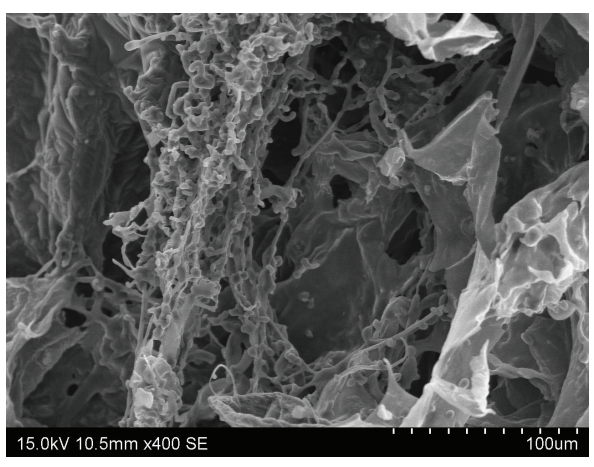

(a)

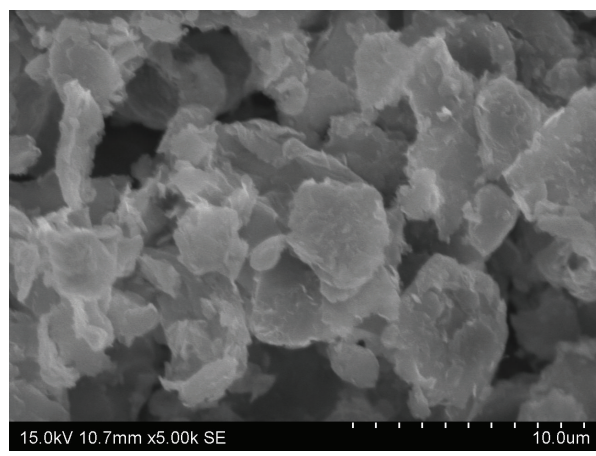

(c)

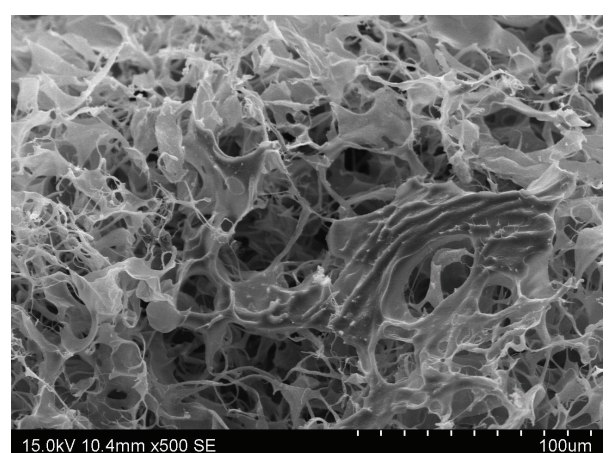

(b)

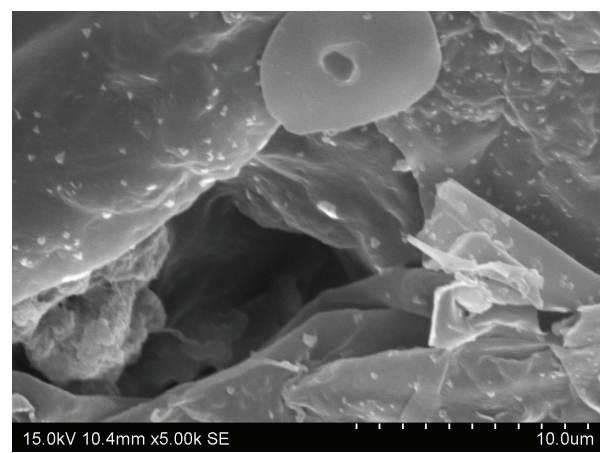

(d)

FIGURE 3: SEM images of (a) xylan- $g$-poly(AA-AMPS), (b) xylan- $g$-poly(AA-AMPS)/MMT at low magnification and (c) MMT, (d) xylan- $g$ poly(AA-AMPS)/MMT at high magnification.

the osmotic pressure difference, resulting in shrinkage of the composite [48].

3.5. Effect of MBA Content on Swelling Capacity. The amount of cross-linking agent determines the cross-linking density of the hydrogel network, which is an important swellingcontrol element. The effect of cross-linker (MBA) to xylan weight ratio on the swelling capacity of the superabsorbent hydrogels was investigated. As shown in Figure 6, the swelling ratio rose from 585 to $864 \mathrm{~g} \mathrm{~g}^{-1}$ when the MBA/xylan weight ratio increased from 0.05 to 0.2 , while it decreased with a further increase in the weight ratio. The hydrophilic polymer chains would dissolve in an aqueous environment with just a few cross-linkers. Therefore, the network cannot be formed efficiently, and the water molecules cannot be held, which results in a decrease in the water absorbency. Contrarily, the excess cross-linking concentration causes the higher crosslinking density and decreases the space of polymer threedimensional network, and consequently, it would not be beneficial to expand the structure and hold a large quantity of water.

3.6. Effect of Monomer Ratio on the Swelling Capacity. The swelling capacity of hydrogels prepared with various weight ratios of AMPS/AA is shown in Figure 7. As can be seen, increasing the AMPS concentration at monomer feed composition, the swelling capacity increased. Swelling and absorption properties are attributed to the presence of hydrophilic groups, such as $-\mathrm{OH}-, \mathrm{CONH}_{-},-\mathrm{CONH}_{2}-$, and $-\mathrm{SO}_{3} \mathrm{H}$ in the network. $-\mathrm{SO}_{3}{ }^{-}$groups associated to AMPS present better affinity than $-\mathrm{COO}^{-}$group of AA. Moreover, the nonionic groups such as $\mathrm{CONH}$ - can improve their salt tolerance.

3.7. Equilibrium Swelling at Various $p H$ Values. The xylan- $g-$ poly(AA-AMPS)/MMT, containing carboxylate, carboxamide, and sulfonate groups, are the majority of anionic-type hydrogels. Ionic superabsorbent hydrogels exhibit swelling changes for a wide range of $\mathrm{pHs}$. Since the swelling capacity of all "ionic" hydrogels is strongly influenced by ionic strength, no buffer solutions are used. Hence, stock NaOH (pH 13.0) and $\mathrm{HCl}(\mathrm{pH}$ 1.0) solutions were diluted with distilled water to reach desired basic and acidic $\mathrm{pH}$ values, respectively. These results are illustrated in Figure 8. The swelling ratios of the superabsorbent hydrogels were finely preserved around $1000 \mathrm{~g} \mathrm{~g}^{-1}$ in a wide range of $\mathrm{pH}(6.0-10.0)$. However, swelling capacity was significantly decreased at $\mathrm{pH}$ lower than 6.0 and higher than 10.0 , which reached to $108 \mathrm{gg}^{-1}$ at $\mathrm{pH} 2.0$ and $148 \mathrm{~g} \mathrm{~g}^{-1}$ at $\mathrm{pH} 12.0$, respectively. In acidic media, the carboxylate and sulfonate anions were protonated. Moreover, the hydrogen-bonding interactions among carboxylate and sulfonate groups were strengthened, which generated the additional physical cross-linking. At higher $\mathrm{pH}$ (6.0-10.0), nearly all of the $-\mathrm{COOH}$ and $-\mathrm{SO}_{3} \mathrm{H}$ groups were converted to $-\mathrm{COO}^{-}$and $-\mathrm{SO}_{3}{ }^{-}$. Consequently, the hydrogen-bonding interaction was eliminated and the electrostatic repulsion 


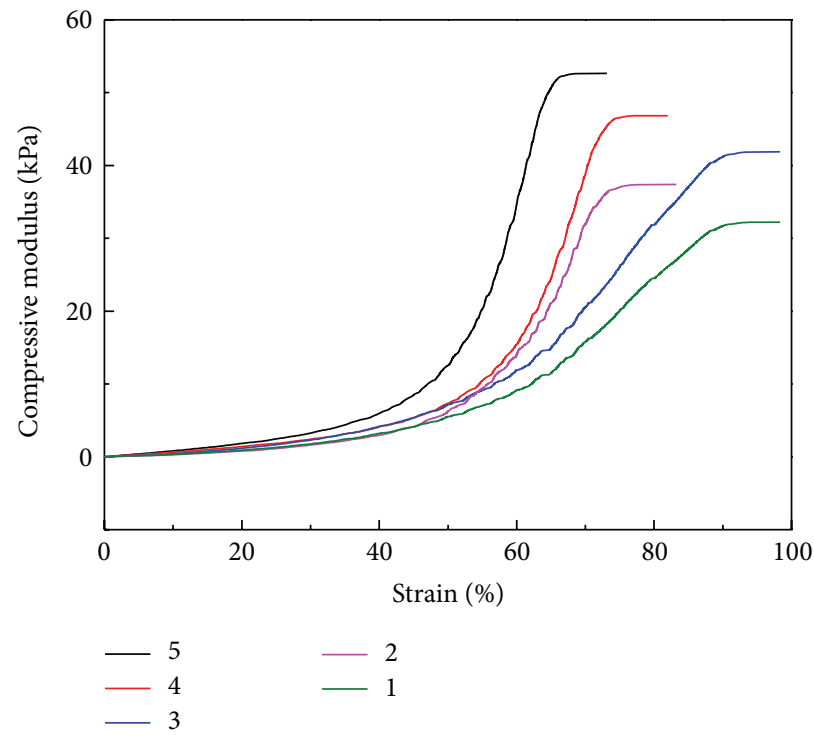

(a)

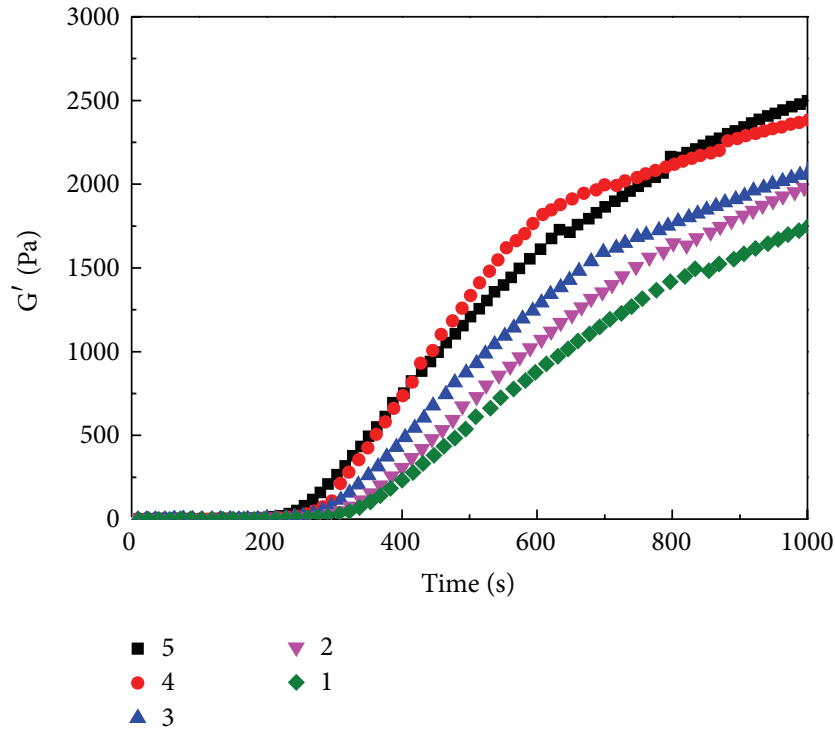

(b)

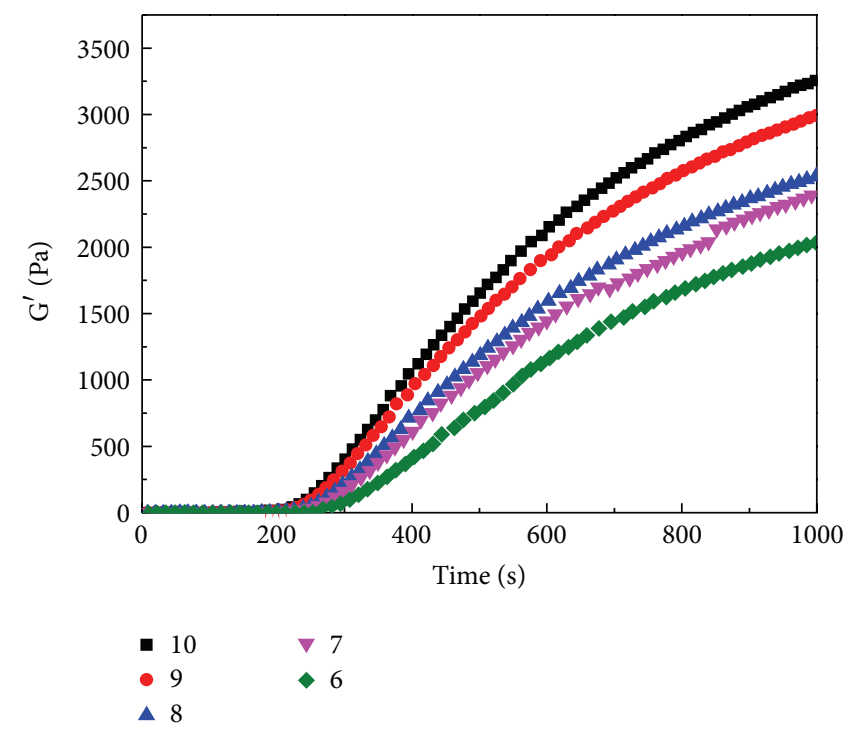

(c)

FIGURE 4: Compressive stress-strain curves for hydrogels with different MMT contents (a). The time dependence of storage modulus $\left(G^{\prime}\right)$ for hydrogels with different MMT contents (b) and different MBA contents (c).

among the anionic groups increased. Therefore, the polymer network tended to swell more. At pHs greater than 10, the excess $\mathrm{Na}^{+}$cations from $\mathrm{NaOH}$ shielded the $-\mathrm{COO}^{-}$ and $-\mathrm{SO}_{3}{ }^{-}$groups, which prevented effective anion-anion repulsion.

3.8. Swelling in Salt Solutions. The characteristics of external solution such as salt concentration and charge valency greatly influence the swelling behavior of the superabsorbent hydrogels. The swelling ratios of hydrogels in aqueous solution of $\mathrm{LiCl}, \mathrm{CaCl}_{2}$, and $\mathrm{FeCl}_{3}$ with various concentrations are shown in Figure 9. Obviously, the swelling ratio decreased with increasing the concentration of external salt solutions. This well-known undesired swelling loss is often attributed to a "charge screening effect" of the additional cations causing a nonperfect anion-anion electrostatic repulsion [49]. Therefore, the osmotic pressure generating from the mobile ion concentration difference between the gel and aqueous phases decreased and resulted in shrinkage of the network. In addition, as shown in Figure 9, the swelling ratio in multivalent cationic saline $\left(\mathrm{CaCl}_{2}\right.$ and $\left.\mathrm{FeCl}_{3}\right)$ solution was almost close to zero at the concentration above $0.1 \mathrm{~mol} \mathrm{~L}^{-1}$, while it reached $31 \mathrm{~g} \mathrm{~g}^{-1}\left(0.1 \mathrm{~mol} \mathrm{~L}^{-1}\right)$ and $21 \mathrm{~g} \mathrm{~g}^{-1}\left(0.25 \mathrm{~mol} \mathrm{~L}^{-1}\right)$ in monovalent cationic solution ( $\mathrm{LiCl}$ ), which are probably due to the complexation of the carboxylate and sulfonate groups 


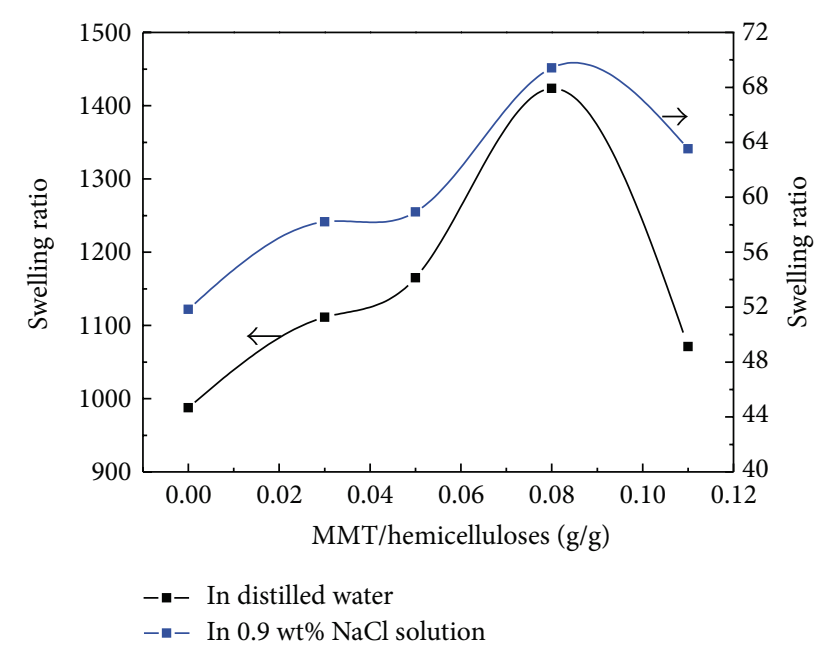

Figure 5: Effect of MMT contents on water absorbency of the hydrogels.

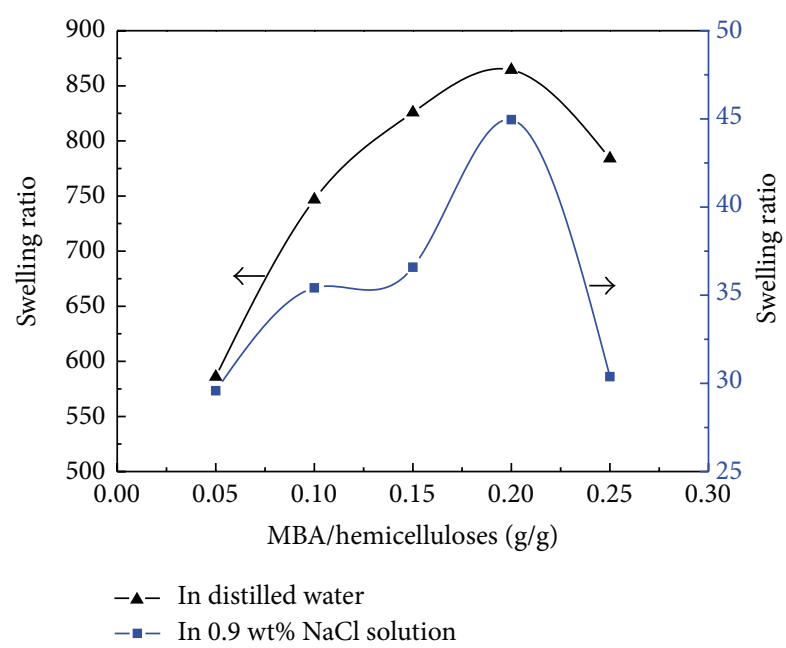

FIGURE 6: Effect of MBA contents on water absorbency of the hydrogels.

with the multivalent cations inducing the formation of the additional cross-link points at the surface of particles. Hence, the network cross-link density was enhanced, resulting in the shrinkage of the network. As a result, the water absorbency was decreased considerably $\left(\mathrm{LiCl}>\mathrm{CaCl}_{2}>\mathrm{FeCl}_{3}\right)$.

3.9. Effect of MMT Content on Water Retention. The water retention ability is an important parameter for hydrogels, especially used in dry and desert regions. The water retention abilities of the hydrogels with different MMT/xylan weight ratios are shown in Figure 10. From this figure, the water retention of the hydrogels was rapidly decreased within $30 \mathrm{~s}$, while small changes in the water retention occurred with prolonging the time. This behavior may be explained as follows: absorbed water in the network of hygrogels can exist in three states: bound, half bond, and free water. Free water is the easiest to remove, compared with bound and half-bond

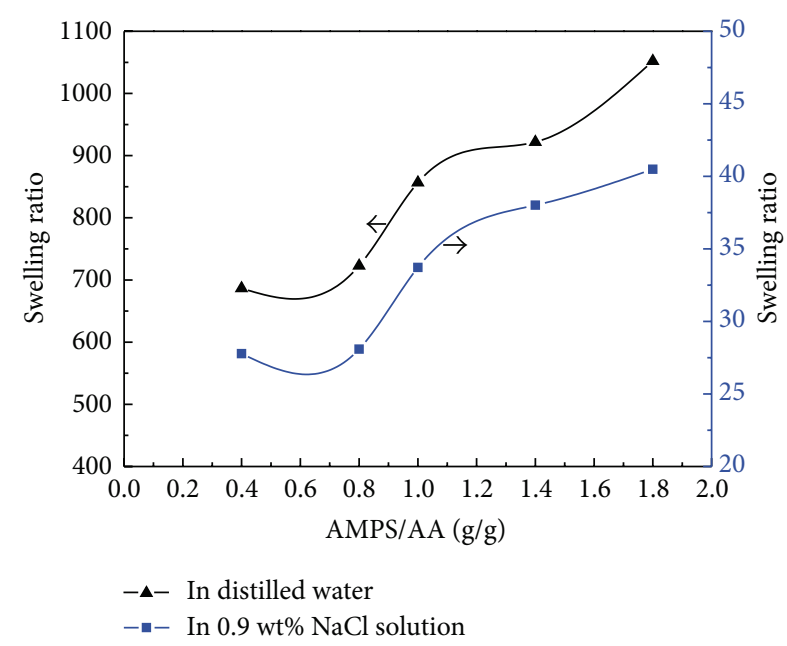

FIGURE 7: Effect of monomer ratios on water absorbency of the hydrogels.

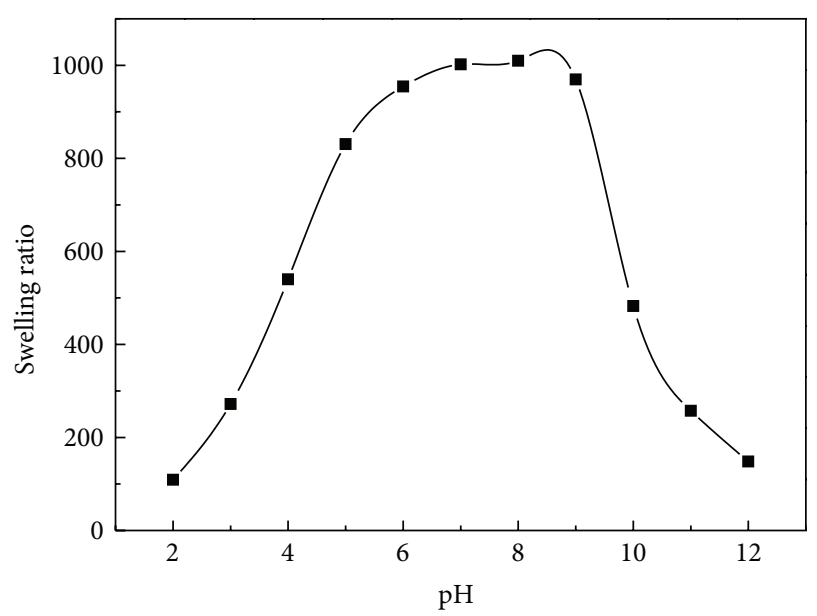

Figure 8: Effect of external $\mathrm{pH}$ on the water absorbency of the hydrogels.

water. Additionally, the water retention of the hydrogels with various MMT/xylan weight ratios of $0.00,0.03,0.05,0.08$, and 0.11 was $65,69,74,60$, and $53 \%$, respectively, centrifuged at $2000 \mathrm{rpm}$ for 360 seconds. It can be concluded that the water retention can be enhanced with the moderate amount of MMT. This may be explained by the barrier effect of polymer/MMT hydrogels [50]. The nano-dispersed MMT in the composite, acted as an additional crosslinking point, impeded the diffusion of the water molecules, and made the diffuse path for water vapor longer. However, a further increase of MMT caused a decrease in water retention, which was probably due to that it was difficult to disperse MMT in the homogeneous network solution at higher MMT content, resulted in decreasing the water retention ability. 


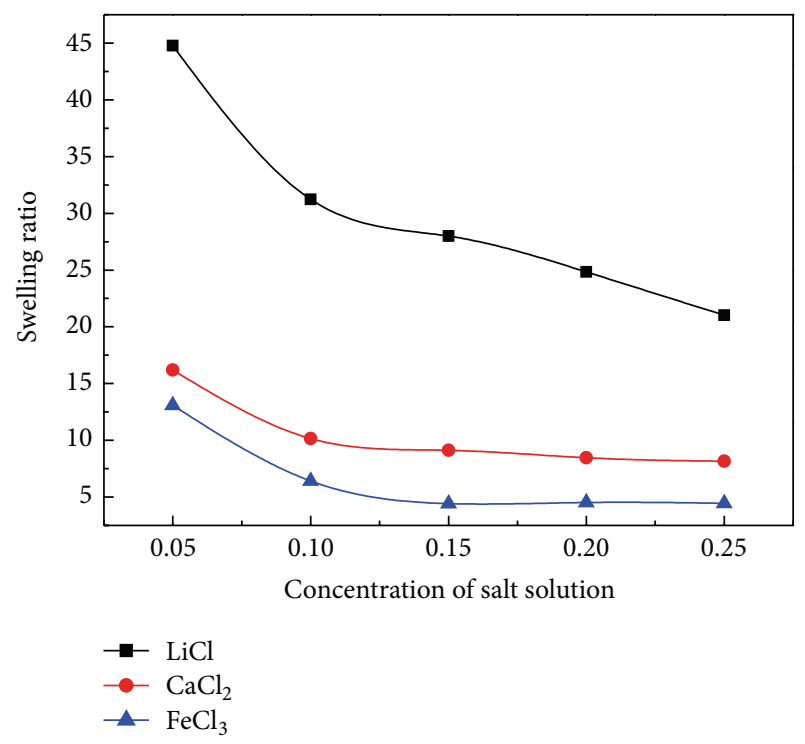

FIGURE 9: Effect of different salt solution on the water absorbency of the hydrogels.

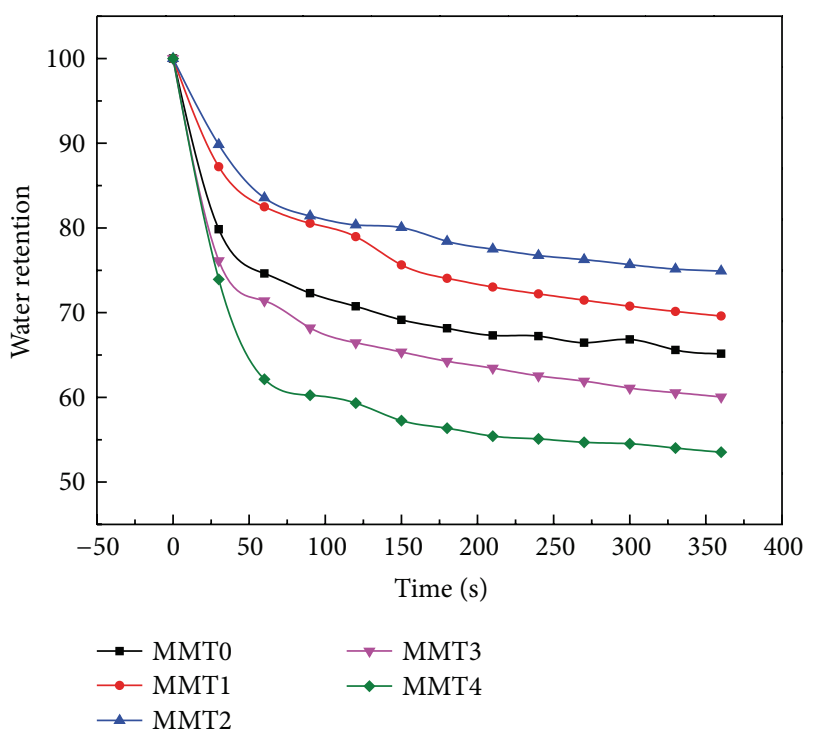

FIGURE 10: Effect of MMT contents on water retention of the hydrogels.

\section{Conclusions}

The superabsorbent hydrogels were prepared by the graft copolymerization of AA and AMPS onto xylan in the presence of a cross-linking agent (MBA), MMT, and KPS as an initiator. The results of FT-IR showed that the superabsorbent hydrogel products comprised cross-linking structures of xylan and MMT with side chains carrying carboxylate, carboxamide, and sulfate. SEM studies showed that a sheet-like structure with significant interconnection formed a threedimensional network, where MMT was finely dispersed to form a homogeneous composition. All the samples exhibited the high compressive modulus $(E)$, about $35-55 \mathrm{KPa}$. The compressive modulus of the hydrogels increased with the increment of the MMT content in the hydrogels, in the order Gel 5> Gel 4> Gel 3> Gel 2> Gel 1. The maximum equilibrium swelling ratios of hydrogels in distilled water and $0.9 \mathrm{wt} \%$ sodium chloride solutions were up to $1423 \mathrm{~g} \mathrm{~g}^{-1}$ and $69 \mathrm{~g} \mathrm{~g}^{-1}$, respectively. The effect of various cationic salt solutions $(\mathrm{LiCl}$, $\mathrm{CaCl}_{2}$, and $\mathrm{FeCl}_{3}$ ) on the swelling has the following order: $\mathrm{Li}^{+}>\mathrm{Ca}^{2+}>\mathrm{Fe}^{3+}$. As a result, these inorganic/organic hydrogels from xylan will have wide applications in the fields of agriculture, foods, tissue engineering, and drug delivery, due to their high swelling capacity and multistimulus response properties.

\section{Conflict of Interests}

The authors declare that there is no conflict of interests regarding the publication of this paper.

\section{Acknowledgments}

This work was supported by Grants from 2013 National Student Research Training Program (SRTP-201310022034), Excellent Youth Scholars of Ministry of Education of China (20110014120006), Ministries of Education (NCET-13-0670 and 113014A), Postdoctoral Science Foundation of China (2012M510328), and Ministry of Science and Technology (973 Project, 2010CB732204).

\section{References}

[1] M. R. Guilherme, A. V. Reis, A. T. Paulino, T. A. Moia, L. H. C. Mattoso, and E. B. Tambourgi, "Pectin-based polymer hydrogel as a carrier for release of agricultural nutrients and removal of heavy metals from wastewater," Journal of Applied Polymer Science, vol. 117, no. 6, pp. 3146-3154, 2010.

[2] F. Puoci, F. Iemma, U. G. Spizzirri, G. Cirillo, M. Curcio, and N. Picci, "Polymer in agriculture: a review," American Journal of Agricultural and Biological Science, vol. 3, no. 1, pp. 299-314, 2008.

[3] T. Ooya, H. Mori, M. Terano, and N. Yui, "Synthesis of a biodegradable polymeric supramolecular assembly for drug delivery," Macromolecular Rapid Communications, vol. 16, no. 4, pp. 259-263, 1995.

[4] P. S. K. Murthy, Y. Murali Mohan, K. Varaprasad, B. Sreedhar, and K. Mohana Raju, "First successful design of semi-IPN hydrogel-silver nanocomposites: a facile approach for antibacterial application," Journal of Colloid and Interface Science, vol. 318 , no. 2, pp. 217-224, 2008.

[5] W. Kangwansupamonkon, W. Jitbunpot, and S. Kiatkamjornwong, "Photocatalytic efficiency of $\mathrm{TiO}_{2} /$ poly[acrylamide-co(acrylic acid)] composite for textile dye degradation," Polymer Degradation and Stability, vol. 95, no. 9, pp. 1894-1902, 2010.

[6] H. Kaşgöz and A. Durmus, "Dye removal by a novel hydrogelclay nanocomposite with enhanced swelling properties," Polymers for Advanced Technologies, vol. 19, no. 7, pp. 838-845, 2008.

[7] L.-M. Zhang, G.-H. Wang, and Z. Xing, "Polysaccharideassisted incorporation of multiwalled carbon nanotubes into sol-gel silica matrix for electrochemical sensing," Journal of Materials Chemistry, vol. 21, no. 12, pp. 4650-4656, 2011. 
[8] F. Brandl, F. Sommer, and A. Goepferich, "Rational design of hydrogels for tissue engineering: impact of physical factors on cell behavior," Biomaterials, vol. 28, no. 2, pp. 134-146, 2007.

[9] K. Y. Lee and D. J. Mooney, "Hydrogels for tissue engineering," Chemical Reviews, vol. 101, no. 7, pp. 1869-1879, 2001.

[10] X. Qu, A. Wirsén, and A.-C. Albertsson, "Novel pH-sensitive chitosan hydrogels: swelling behavior and states of water," Polymer, vol. 41, no. 12, pp. 4589-4598, 2000.

[11] S.-Y. Yang and C.-Y. Huang, "Plasma treatment for enhancing mechanical and thermal properties of biodegradable PVA/starch blends," Journal of Applied Polymer Science, vol. 109, no. 4, pp. 2452-2459, 2008.

[12] F. Lenzi, A. Sannino, A. Borriello, F. Porro, D. Capitani, and G. Mensitieri, "Probing the degree of crosslinking of a cellulose based superabsorbing hydrogel through traditional and NMR techniques," Polymer, vol. 44, no. 5, pp. 1577-1588, 2003.

[13] S. Hua and A. Wang, "Synthesis, characterization and swelling behaviors of sodium alginate-g-poly(acrylic acid)/sodium humate superabsorbent," Carbohydrate Polymers, vol. 75, no. 1, pp. 79-84, 2009.

[14] A. Pourjavadi and H. Ghasemzadeh, "Carrageenan-gpoly(acrylamide)/poly(vinylsulfonic acid, sodium salt) as a novel semi-IPN hydrogel: synthesis, characterization, and swelling behavior," Polymer Engineering and Science, vol. 47, no. 9, pp. 1388-1395, 2007.

[15] Y. Gong, C. Wang, R. C. Lai, K. Su, F. Zhang, and D.A. Wang, "An improved injectable polysaccharide hydrogel: modified gellan gum for long-term cartilage regeneration in vitro," Journal of Materials Chemistry, vol. 19, no. 14, pp. 19681977, 2009.

[16] M. S. Lindblad, A.-C. Albertsson, E. Ranucci, M. Laus, and E. Giani, "Biodegradable polymers from renewable sources: rheological characterization of hemicellulose-based hydrogels," Biomacromolecules, vol. 6, no. 2, pp. 684-690, 2005.

[17] A.-C. Albertsson, J. Voepel, U. Edlund, O. Dahlman, and M. Söderqvist-Lindblad, "Design of renewable hydrogel release systems from fiberboard mill wastewater," Biomacromolecules, vol. 11, no. 5, pp. 1406-1411, 2010.

[18] A. A. Roos, U. Edlund, J. Sjöberg, A.-C. Albertsson, and H. Stalbrand, "Protein release from galactoglucomannan hydrogels: influence of substitutions and enzymatic hydrolysis by $\beta$ mannanase," Biomacromolecules, vol. 9, no. 8, pp. 2104-2110, 2008.

[19] Y. Lu, L. Zhang, X. Zhang, and Y. Zhou, "Effects of secondary structure on miscibility and properties of semi-IPN from polyurethane and benzyl konjac glucomannan," Polymer, vol. 44, no. 21, pp. 6689-6696, 2003.

[20] U. Edlund and A.-C. Albertsson, "A microspheric system: hemicellulose-based hydrogels," Journal of Bioactive and Compatible Polymers, vol. 23, no. 2, pp. 171-186, 2008.

[21] A. M. Karaaslan, M. A. Tshabalala, and G. Buschle-Diller, "Wood hemicellulose/chitosan-based semi: interpenetrating network hydrogels: mechanical, swelling and controlled drug release properties," BioResources, vol. 5, no. 2, pp. 1036-1054, 2010.

[22] X.-W. Peng, L.-X. Zhong, J.-L. Ren, and R.-C. Sun, "Highly effective adsorption of heavy metal ions from aqueous solutions by macroporous xylan-rich hemicelluloses-based hydrogel," Journal of Agricultural and Food Chemistry, vol. 60, no. 15, pp. 3909-3916, 2012.

[23] X.-W. Peng, J.-L. Ren, L.-X. Zhong, F. Peng, and R.-C. Sun, "Xylan-rich hemicelluloses-graft-acrylic acid ionic hydrogels with rapid responses to $\mathrm{pH}$, salt, and organic solvents," Journal of Agricultural and Food Chemistry, vol. 59, no. 15, pp. 82088215, 2011.

[24] T. Ishii, "Acetylation at O-2 of arabinofuranose residues in feruloylated arabinoxylan from bamboo shoot cell-walls," Phytochemistry, vol. 30, no. 7, pp. 2317-2320, 1991.

[25] M. C. Figueroa-Espinoza and X. Rouau, "Oxidative crosslinking of pentosans by a fungal laccase and horseradish peroxidase: mechanism of linkage between feruloylated arabinoxylans," Cereal Chemistry, vol. 75, no. 2, pp. 259-265, 1998.

[26] A. Skendi, C. G. Biliaderis, M. S. Izydorczyk, M. Zervou, and P. Zoumpoulakis, "Structural variation and rheological properties of water-extractable arabinoxylans from six Greek wheat cultivars," Food Chemistry, vol. 126, no. 2, pp. 526-536, 2011.

[27] E. Carvajal-Millan, S. Guilbert, M.-H. Morel, and V. Micard, "Impact of the structure of arabinoxylan gels on their rheological and protein transport properties," Carbohydrate Polymers, vol. 60, no. 4, pp. 431-438, 2005.

[28] M. S. Izydorczyk and C. G. Biliaderis, "Cereal arabinoxylans: advances in structure and physicochemical properties," Carbohydrate Polymers, vol. 28, no. 1, pp. 33-48, 1995.

[29] J. Zhang and A. Wang, "Study on superabsorbent composites. IX: synthesis, characterization and swelling behaviors of polyacrylamide/clay composites based on various clays," Reactive and Functional Polymers, vol. 67, no. 8, pp. 737-745, 2007.

[30] X. Shi, S. Xu, J. Lin, S. Feng, and J. Wang, "Synthesis of $\mathrm{SiO}_{2}$-polyacrylic acid hybrid hydrogel with high mechanical properties and salt tolerance using sodium silicate precursor through sol-gel process," Materials Letters, vol. 63, no. 5, pp. $527-529,2009$

[31] P. K. Sahoo and P. K. Rana, "Synthesis and biodegradability of starch-g-ethyl methacrylate/sodium acrylate/sodium silicate superabsorbing composite," Journal of Materials Science, vol. 41, no. 19 , pp. $6470-6475,2006$.

[32] D. Gao, R. B. Heimann, J. Lerchner, J. Seidel, and G. Wolf, "Development of a novel moisture sensor based on superabsorbent poly(acrylamide)-montmorillonite composite hydrogels," Journal of Materials Science, vol. 36, no. 18, pp. 4567-4571, 2001.

[33] Y. Bao, J. Ma, and N. Li, "Synthesis and swelling behaviors of sodium carboxymethyl cellulose-g-poly(AA-co-AM-coAMPS)/MMT superabsorbent hydrogel," Carbohydrate Polymers, vol. 84, no. 1, pp. 76-82, 2011.

[34] F. Peng, J.-L. Ren, F. Xu, J. Bian, P. Peng, and R.-C. Sun, "Fractionation of alkali-solubilized hemicelluloses from delignified populus gansuensis: structure and properties," Journal of Agricultural and Food Chemistry, vol. 58, no. 9, pp. 5743-5750, 2010.

[35] P. Uthirakumar, K. S. Nahm, Y. B. Hahn, and Y.-S. Lee, "Preparation of polystyrene/montmorillonite nanocomposites using a new radical initiator-montmorillonite hybrid via in situ intercalative polymerization," European Polymer Journal, vol. 40, no. 11, pp. 2437-2444, 2004.

[36] M. Kačuráková, N. Wellner, A. Ebringerovaá, Z. Hromaádkovaá, R. H. Wilson, and P. S. Belton, "Characterisation of xylan-type polysaccharides and associated cell wall components by FT-IR and FT-Raman spectroscopies," Food Hydrocolloids, vol. 13, no. 1, pp. 35-41, 1999.

[37] A. Ebringerova, Z. Hromadkova, J. Alfoldi, and G. Berth, "Structural and solution properties of corn cob heteroxylans," Carbohydrate Polymers, vol. 19, no. 2, pp. 99-105, 1992. 
[38] W. Wang, Q. Wang, and A. Wang, "PH-responsive carboxymethylcellulose-g-poly(sodium acrylate)/polyvinylpyrrolidone semi-IPN hydrogels with enhanced responsive and swelling properties," Macromolecular Research, vol. 19, no. 1, pp. 57-65, 2011.

[39] M. Dalaran, S. Emik, G. Güçlü, T. B. Iyim, and S. Özgümüş, "Removal of acidic dye from aqueous solutions using poly(DMAEMA-AMPS-HEMA) terpolymer/MMT nanocomposite hydrogels," Polymer Bulletin, vol. 63, no. 2, pp. 159-171, 2009.

[40] S. W. Xu, J. P. Zheng, L. Tong, and K. De Yao, "Interaction of functional groups of gelatin and montmorillonite in nanocomposite," Journal of Applied Polymer Science, vol. 101, no. 3, pp. 1556-1561, 2006.

[41] H. A. Patel, R. S. Somani, H. C. Bajaj, and R. V. Jasra, "Synthesis and characterization of organic bentonite using Gujarat and Rajasthan clays," Current Science, vol. 92, no. 7, pp. 1004-1009, 2007.

[42] M. Baek, J.-H. Choy, and S.-J. Choi, "Montmorillonite intercalated with glutathione for antioxidant delivery: synthesis, characterization, and bioavailability evaluation," International Journal of Pharmaceutics, vol. 425, no. 1-2, pp. 29-34, 2012.

[43] D. R. Nisbet, K. E. Crompton, S. D. Hamilton et al., "Morphology and gelation of thermosensitive xyloglucan hydrogels," Biophysical Chemistry, vol. 121, no. 1, pp. 14-20, 2006.

[44] J. Wang, W. Wang, and A. Wang, "Synthesis, characterization and swelling behaviors of hydroxyethyl cellulose-g-poly(acrylic acid)/attapulgite superabsorbent composite," Polymer Engineering and Science, vol. 50, no. 5, pp. 1019-1027, 2010.

[45] F. Santiago, A. E. Mucientes, M. Osorio, and C. Rivera, "Preparation of composites and nanocomposites based on bentonite and poly(sodium acrylate). Effect of amount of bentonite on the swelling behaviour," European Polymer Journal, vol. 43, no. 1, pp. $1-9,2007$.

[46] T. Gao, W. Wang, and A. Wang, "A pH-sensitive composite hydrogel based on sodium alginate and medical stone: synthesis, swelling, and heavy metal ions adsorption properties," Macromolecular Research, vol. 19, no. 7, pp. 739-748, 2011.

[47] C. Chang, S. Chen, and L. Zhang, "Novel hydrogels prepared via direct dissolution of chitin at low temperature: structure and biocompatibility," Journal of Materials Chemistry, vol. 21, no. 11, pp. 3865-3871, 2011.

[48] L. Wu and M. Liu, "Slow-release potassium silicate fertilizer with the function of superabsorbent and water retention," Industrial and Engineering Chemistry Research, vol. 46, no. 20, pp. 6494-6500, 2007.

[49] M. Sadeghi and M. Yarahmadi, "Synthesis and characterization of superabsorbent hydrogel based on chitosan-g-poly (acrylic acid-coacrylonitrile)," African Journal of Biotechnology, vol. 10, no. 57, pp. 12265-12275, 2011.

[50] H. Qiu and J. Yu, "Polyacrylate/(carboxymethylcellulose modified montmorillonite) superabsorbent nanocomposite: preparation and water absorbency," Journal of Applied Polymer Science, vol. 107, no. 1, pp. 118-123, 2008. 

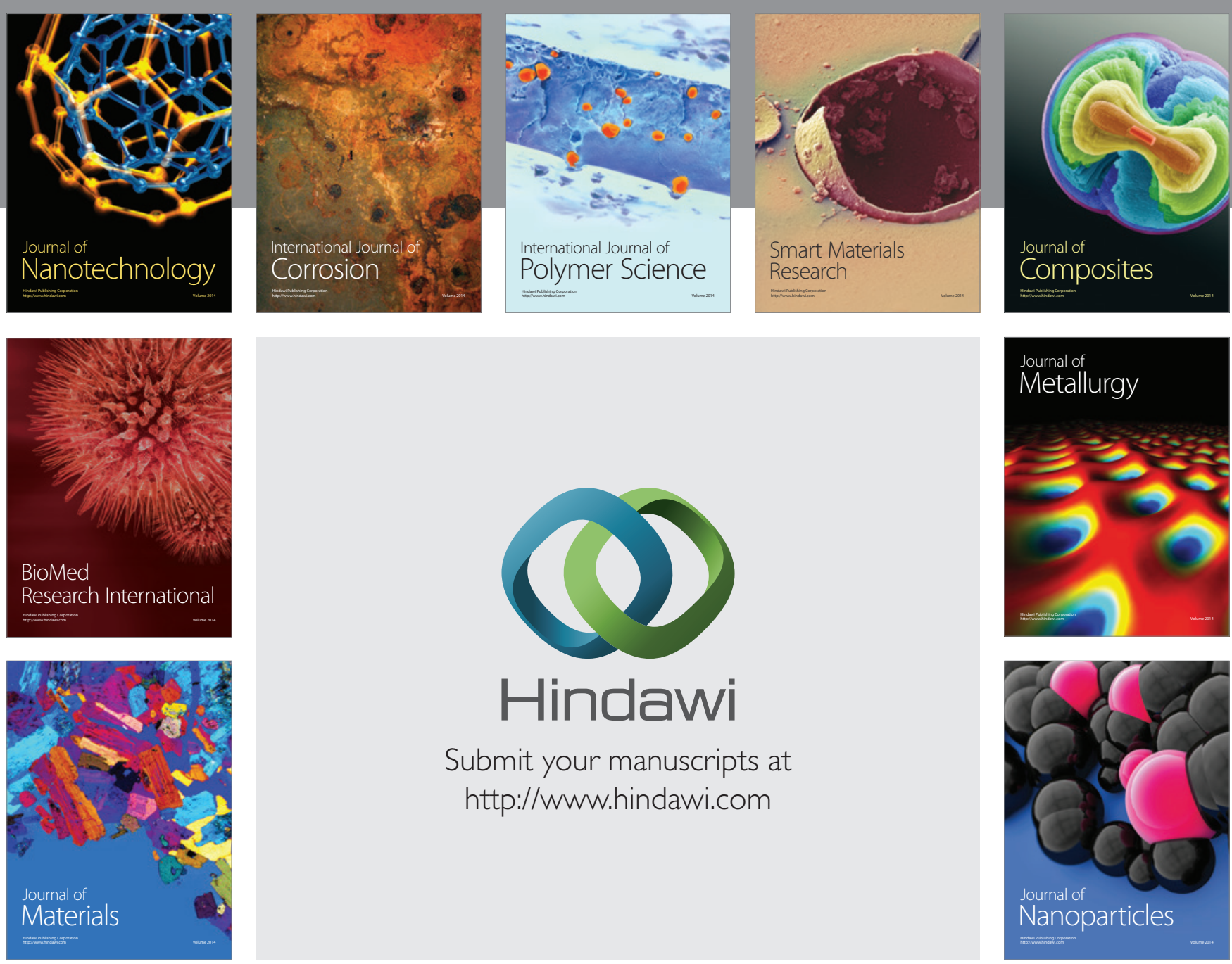

Submit your manuscripts at http://www.hindawi.com
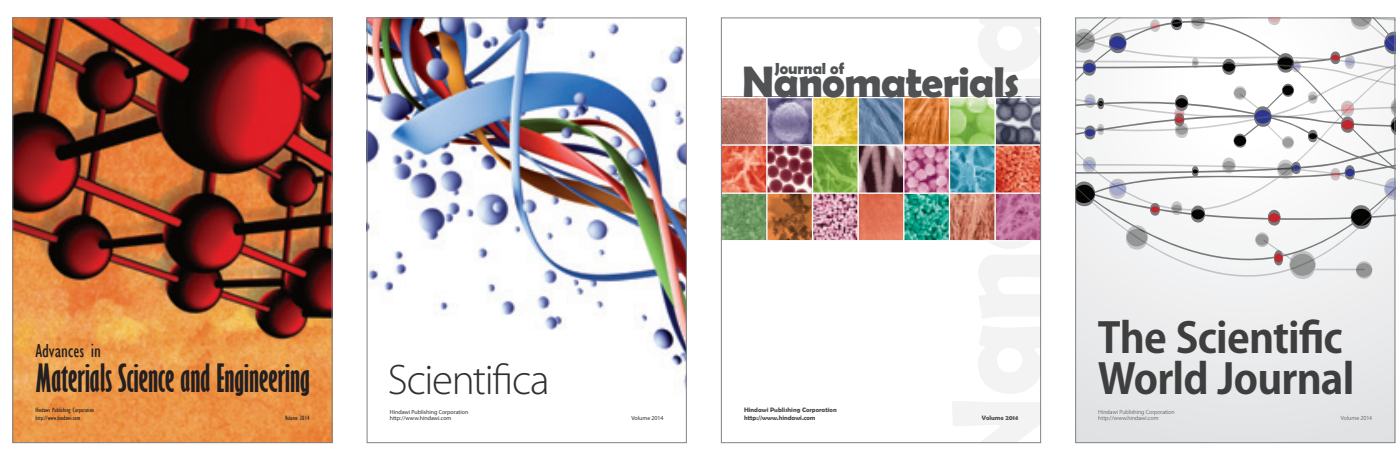

\section{The Scientific World Journal}
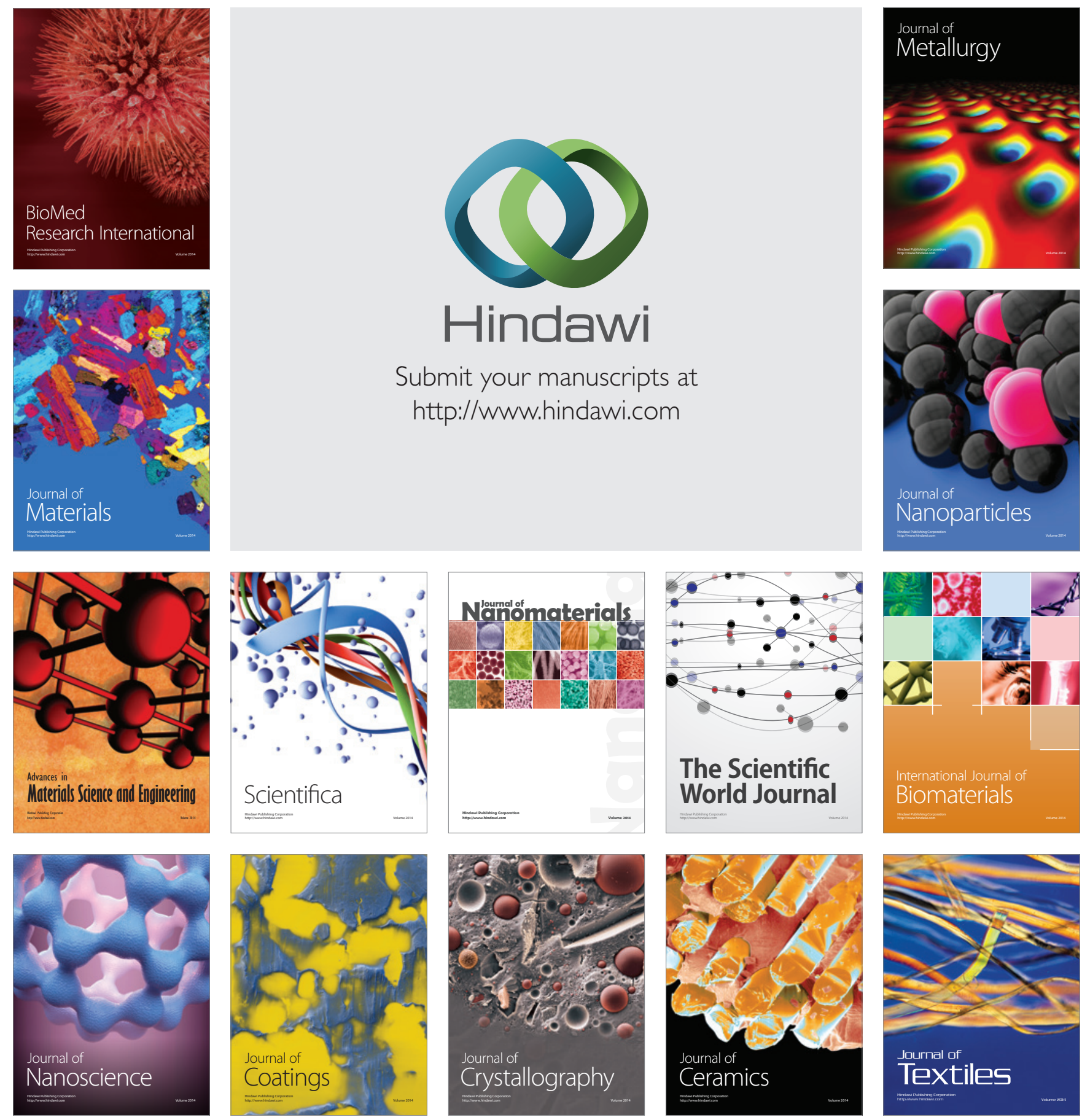